\title{
Compor o reconhecimento: explorar laços com os outros na escola
}

\author{
José Manuel Resende ${ }^{1}$ \\ ORCID: 0000-0002-7233-2237 \\ Luís Gouveia² \\ ORCID: 0000-0002-6518-2330 \\ David Beirante ${ }^{2}$ \\ ORCID: 0000-0001-9674-217X \\ Lucas Freitas de Souza ${ }^{1}$ \\ ORCID: 0000-0001-7641-7855
}

\section{Resumo}

0 presente artigo insere-se em um projeto de investigação centrado na problemática da hospitalidade na forma como os alunos agem nos territórios escolares, visibilizada por meio de experiências inóspitas e hospitaleiras vivenciadas por esses atores no decurso das sociabilidades escolares. No quadro desta problemática, pretende-se, em particular, observar como os alunos qualificados como estrangeiros se ligam à escola e, através desses laços, analisar as maneiras como se relacionam com os outros, na figura dos seus pares, em um contexto de transformação na morfologia escolar nas últimas décadas, decorrente do incremento do número de alunos estrangeiros que se matriculam nos ciclos da escolaridade obrigatória em Portugal. Mediante o quadro teórico comumente designado por sociologia pragmática, tenciona-se analisar como alunos se envolvem em diferentes e compostos regimes de ação que visam a fazer o comum no plural nos respectivos estabelecimentos de ensino. Articulam-se, para o efeito, dados de entrevistas semidiretivas e observações etnográficas levadas a cabo em duas escolas públicas do ensino médio português e que têm como traço comum albergarem fortes contingentes de alunos oriundos de contextos de imigração e com diversas nacionalidades. Incidindo o olhar sociológico sobre vários espaços tipificados que compõem o território escolar, é nas exteriorizações por parte desses alunos estrangeiros inquiridos em torno de acontecimentos efervescentes e do modo como habitam a escola que é tratada e evidenciada a problemática do reconhecimento nomeadamente, as composições do reconhecimento do aluno na sua figura de estrangeiro e as diversas experiências em que esse reconhecimento é ou não experienciado.

\section{Palavras-chave}

Estrangeiro - Sociabilidades escolares - Escola justa e direitos humanos - Regimes de ação.

1- * Universidade de Évora, Portugal. Contatos: josemenator@gmail.com; souza.Ifd@outlook.com.

2- ** Centro Interdisciplinar de Ciências Sociais (CICS.NOVA), Lisboa, Portugal. Contatos: Icgouveia86@gmail.com; dbeirante@gmail.com. 


\section{Forming recognition: exploring bonds with others at school}

\section{Abstract}

This article is inserted in an investigation project centered on the problem of hospitality in the way students act in school grounds, viewed through inhospitable and hospitable experiences these actors lived throughout school sociabilities. In the framework of this problem, we intend to observe, in particular, how students who qualify as foreign connect to the school, and, through these bonds, the way they relate to others, in the figure of their peers, within a context of a transformation in school morphology in the last few decades stemming from the rise in the number of foreign students enrolled in the cycles of mandatory schooling in Portugal. Through the theoretical framework commonly designated pragmatic sociology, we intend to analyze how students are engaged in different and compounded regimes of action that seek to make the common in the plural in their respective teaching establishments. For that purpose, we have articulated data from semi-structured interviews and ethnographic observations conducted in two public schools within the Portuguese Secondary Education system, with a common trait of hosting large contingents of students originating from contexts of immigration and of different nationalities. Shining a sociological light on several typified spaces that make up the school territory, it is in the exteriorizations by these foreign students when inquired regarding pressing events and about the way in which they inhabit the school that we address and point out the problem of recognition-namely the forming of the recognition of students in their status as foreign and the several experiences in which this recognition is or is not experienced.

\section{Keywords}

Foreign - school sociabilities - Fair School and human rights - Regimes of action

\section{O que faz da escola a escola?}

Esta interrogação parece não fazer qualquer sentido. Quem não ousaria responder com tranquilidade a essa interrogação? Hoje, com uma escolarização que se massifica em velocidades desiguais, não ter tido qualquer experiência escolar já não é tão habitual como outrora. Prudentemente, não se generaliza a apropriação dessa experiência, nem em Portugal e, muito menos, em outras geografias.

No entanto, a massificação escolar no país tem tido como consequência não só a permanência mais prolongada de gerações mais novas que em outras circunstâncias já tinham abandonado a escola, mas também o crescimento de matrículas de alunos provenientes de famílias migrantes (SEABRA et al., 2011; SEABRA, 2010; MACHADO; 
MATIAS; LEAL, 2005) ${ }^{3}$. Portugal não é um país marcado, em termos históricos, por rotas de imigração contínua ou por migrações cíclicas. Pelo contrário, tendo sido historicamente um país de emigração periódica. No entanto, hoje em dia tem acolhido um número crescente de famílias que aqui têm procurado se fixar para viver (PEIXOTO, 2007).

Apesar da verificação das transformações morfológicas do estudantado nas escolas do Ensino Básico e Secundário, usando o princípio da cautela, pensamos que não são vãs haver ideias, mais ou menos convictas, sobre aquilo que é a escola, ou sobre aquilo que se pode fazer na escola. Mesmo que a experiência não tenha sido exercitada na primeira pessoa, ou que tenha sido praticada em momentos curtos das suas trajetórias de vida, por mediação ou pessoalmente, os indivíduos são quase todos capazes de emitir juízos sobre essa instituição.

Nem sempre foi assim. A história da escolarização mostra bem como foi tardia a sua implementação em muitos países de diferentes cartografias. 0 mesmo tem sido referido para o caso português (VIEIRA, 2003; ALMEIDA; VIEIRA, 2000; RAMOS, 1988). A morosidade nossa nesse empreendimento tem sido justificada por diversas razões. Uma prende-se com a edificação de uma rede de escolas, projeto lentamente concretizado, e que ficou sempre aquém do desejável (RODRIGUES et al., 2015).

Mas o atraso escolar é também justificado pela falta de apetência das pessoas em buscar na escola outros conhecimentos. Não estavam talhadas para a aquisição dos saberes escolares. Em outras palavras, a escolarização não fazia sentido (CANDEIAS, 2001).

Finalmente, a terceira razão era a difícil missão em administrar o medo de que esse desejo, em vez de pacificar as relações entre os indivíduos, agudizasse o conflito e a violência da parte daqueles que, escolarizados, buscam outras oportunidades no sentido de concretizarem outras expectativas. Nesse caso, o susto era admitir a possibilidade de a escolarização tornar possível mobilidades sociais, profissionais e/ou territoriais (RESENDE, 2003; MÓNICA, 1978).

É certo que essas razões não esgotam os fundamentos da tardança da sua extensão. Não importa aqui tal desiderato. A sua importância reside na acentuação da demora na construção dos equipamentos escolares considerados necessários às aprendizagens, mas também da extensão dessas aos diversos ciclos dedicados à transmissão dos saberes disciplinares a que a escolarização se compromete no quadro do seu programa institucional (RODRIGUES et al., 2015).

Sejam quais forem as tonalidades da história da escolarização portuguesa, o nosso propósito tem sido o de dar contribuições analíticas que permitam conhecer a escola. Saber

\footnotetext{
3- Para dar um exemplo do número de estudantes estrangeiros matriculados em estabelecimentos do Ensino Secundário em Portugal, recorremos às estatísticas oficiais relativas ao ano letivo de 2017/18 (DGEEC, 2019). Esse ano escolar é o escolhido, porque se refere ao ano letivo onde esta pesquisa exploratória foi lançada e realizada, entre setembro de 2017 e julho de 2018. De acordo com os dados oficiais, estavam matriculados nesse ciclo de ensino 17417 alunos de cerca 130 nacionalidades, quer no ensino público, quer no ensino privado. A composição morfológica dos estudantes varia muito consoante a nacionalidade. Destacam-se os alunos de nacionalidade brasileira - 5419 - seguindo-se os alunos cabo-verdianos - 1881 -, os alunos angolanos - 1807 - e os alunos de famílias guineenses - 1121-, de São Tomé e Príncipe - 1056 - e, para finalizar, 821 alunos ucranianos. Não se desprezam os contingentes de alunos de nacionalidade chinesa, nem o peso numérico de alunos com nacionalidades de países que fazem parte da União europeia, como por exemplo, romenos, franceses, espanhóis, alemães, italianos, e búlgaros. 0 mesmo acontece com os alunos de famílias inglesas - 241 - muito concentrados na região algarvia a sul do País. Uma parte significativa desse contingente frequenta escolas na área metropolitana de Lisboa e do Porto. Para uma análise mais circunscrita da composição desses alunos, confira https://www.dgeec.mec.pt/np4/97/.
} 
da escola com aproximações rigorosas tem-nos exigido usar diferentes lentes (RESENDE, GOUVEIA; BEIRANTE, 2020; RESENDE; BEIRANTE, 2014; DIONÍSIO, 2018; RESENDE; DIONÍSIO, 2016; CAETANO, 2016, 2018).

E o seu uso variado tem propiciado-nos decifrar os seus meandros com travessuras apoiadas por múltiplas entradas. Só assim tem sido possível averiguar nos últimos 15 anos as contribuições de professores e alunos sobre o que faz da escola a escola (RESENDE, 2010; RESENDE; GOUVEIA, 2013).

Esta que agora vos propomos é outra passagem, isto é, outro lance para conhecer a escola portuguesa a partir de um exemplo singular. Agora, o objetivo é interpretar como os alunos de nacionalidade estrangeira conferem sentidos sobre o que faz para si a escola ser escola em um estabelecimento de ensino localizado na capital do país. Isto é, ensaiamos saber com algum pormenor aquilo que os adolescentes ali matriculados são capazes de fazer para que as suas experiências escolares os identifiquem com a escola.

Faz-se, então, uma aproximação àquilo que os faz, naqueles contextos, serem eles mesmos na escola. Ora, essa opção implica observar como os alunos qualificados como estrangeiros se ligam à escola através dos outros ${ }^{4}$.

É por meio dessas ligações que é possível descortinar as maneiras como se relacionam uns colegas com os outros naquela escola. Acompánhamos as artes de fazerem o comum no plural (BOLTANSKI; THÉVENOT, 2006; THÉVENOT, 2006; THÉVENOT, 2015; RESENDE; MARTINS, 2015) em cada um dos instantes que foram captados pelos registros de uma das estudantes de sociologia que mergulhou a fundo na escola sediada em Lisboa ${ }^{5}$.

\footnotetext{
4- E é sobre os modos como alguns adolescentes entrevistados ensaiaram essa sua capacitação de autonomia que recai o nosso olhar sociológico para interpretar os dados recolhidos por oito jovens estudantes de sociologia. 0 trabalho de campo decorreu entre setembro de 2017 a julho de 2018 em duas escolas do ensino secundário: uma situada na capital do país e que tem alunos matriculados de diversas nacionalidades; outra localizada no concelho de Oeiras, território administrativo contíguo ao primeiro, que apresentava um menor número de alunos registrados como de nacionalidade estrangeira. Este estudo exploratório intitulado - Entre a escola e o bairro: estranheza, estranhamento e hospitalidade incluiu a aplicação de diversos instrumentos de observação ao longo de cerca de 10 meses ininterruptos. Os jovens assistiram a aulas de diferentes disciplinas e por cada aula assistida produziram um relatório sobre o modo como os alunos interagiam uns com os outros por via da mediação do professor, ou por iniciativas próprias e a propósito de qualquer coisa. Em outros momentos, observaram os alunos no bar/lanchonete da escola onde decorriam os momentos das refeições escolares; outros espaços onde foram tomadas notas sobre como os adolescentes se moviam uns com os outros em diversas atividades foram: a biblioteca, os espaços do recreio, dando-se enfoque especial aos espaços juntos dos recintos de jogos e à entrada das duas escolas. Para além desses registros, cada um dos oito estudantes de sociologia envolvidos no projeto entrevistaram 4 estudantes de nacionalidade estrangeira matriculados em cada uma das escolas. No total, foram feitas 32 entrevistas aprofundadas. Entrevistaram 0 mesmo número de meninas e meninos no arco de idades da adolescência a entrar na idade juvenil - dos 15/16 aos 17/18 anos. E, finalmente, foi construído um questionário por cenários aplicado nas duas escolas em março e abril. Foram inquiridos todos os alunos inscritos no $12^{\circ}$ ano de escolaridade, 0 ano terminal do Ensino Secundário em Portugal. Na escola do conselho de Oeiras frequentam alunos do último ciclo do Ensino Básico - Ensino Fundamental - e do Ensino Secundário - Ensino Médio. É uma escola com uma arquitetura moderna com amplos espaços de recreio intercalado por pavilhões (3) com salas de aula, laboratórios e espaço para a educação física, e um pavilhão central com a secretaria, a sala da direção e salas para reuniões dos órgãos de governação escolar, a sala de professores, o bar/lanchonete, a biblioteca, com uma sala grande destinada a eventos públicos. A escola situada no conselho de Lisboa é uma construção do final dos anos 60, mas remodelada em 2007/09, e alberga exclusivamente alunos do Ensino Secundário. As salas de aula, os laboratórios, a biblioteca, o gabinete de psicologia ocupacional, diversos gabinetes, a sala dos professores e o bar/lanchonete encontram-se espalhadas por pavilhões, com longos corredores que os une, uns no térreo e outros num andar de cima. A sala dos professores fica perto do bar e da sala da direção da escola e da secretaria escolar e de salas destinadas a reuniões dos órgãos do estabelecimento de ensino. Próximas das escolas estão cafés e restaurantes onde os alunos se encontram, ou durante os intervalos, ou nos tempos de passagem do turno matinal para o turno da tarde. Esses espaços são territórios importantes para a sociabilidade escolar.

5- Anastasya Kasprova, na época estudante do $2^{\circ}$ ano da graduação de Sociologia da Faculdade de Ciências Sociais, foi uma das jovens que integrou a equipa de pesquisa. Era uma equipa formada por seis estudantes da mesma turma. Um dos autores deste texto foi professor deste magnífico grupo de jovens. Anastasya trabalhou na escola sediada em Lisboa com Rita Almeida e João Pedro Timóteo. Na escola do conselho de Oeiras trabalharam Margarida Lima, André Caixinha e Marta Cunha. Sob orientação científica e metodológica do Professor José Manuel Resende e
} 
Dos extratos do seu diário de bordo, retirámos alguns excertos eleitos como importantes para analisar as composições do reconhecimento na escola do aluno na sua figura de estrangeiro (SIMMEL, 1999; 2004; STAVO-DEBAUGE, 2017). Retornaremos, mais tarde, à mesma viagem, mas agora socorrendo-nos de informações recolhidas de entrevistas que foram realizadas pela mesma pesquisadora.

Buscamos nos atos de reconhecimento a que são votados os alunos observados o ponto delicado da nossa análise (SETTON; MERTUCCELLI, 2015). Para atenuar deslizes perigosos que possam orientar a emparelhar a análise com interpretações encantatórias por excesso, o cuidado residiu justamente na tentativa de trazer para as reflexões tudo aquilo a que os alunos foram capazes de expressar sobre as suas experiências escolares.

Dos testes por eles revelados nas suas implicações com o ambiente e a ambiência escolares, destacámos as suas realizações consigo próprios através dos outros, o que nos remete para uma afınação daquilo que pretendemos afırmar: a alteridade do outro (RICOEUR, 1990, 1995, 2004). 0 outro aqui não aparece na figura do eu desconhecido e generalizado (MEAD, 2006), em certo sentido, descontextualizado ou fora de um dado ambiente concreto.

Por outro lado, o propósito não é implicar o outro na comparação consigo mesmo. Ensaiámos ir mais longe quanto nos foi possível. Afınámos progressivamente a figura do outro a partir de si mesmo enquanto esse outro com quem se vai relacionando durante a sua permanência na escola e fora dela (RICOEUR, 1990, 2004).

É certo que não esvaziámos a relação do si mesmo enquanto outro de todas as experiências de afetação, isto é, dos atos de afetar o outro e de ser afetado pelo outro (BREVIGLIERI, 2016) Mas não deixámos de observar se o si mesmo enquanto o outro aparecia também naquele contexto com voz, e não somente sujeito ao mando da voz dos outros.

De outro lado, também não descurámos a outra face da problemática enformada por uma antropologia capacitária que, na e pela escolarização, prepara o si mesmo enquanto um outro para granjear a autonomia de si face ao outro (BREVIGLIERI, 2007a). Se a preparação para ter voz é um sinal dessa maturidade que se vai conquistando na adolescência, e que é uma das manifestações da autonomia singularizada no si mesmo enquanto outro, não é possível descartar experiências invertidas, isto é, inversas (BREVIGLIERI, 2016).

\footnotetext{
durante 0 ano de sabática (2017/18), esses jovens fizeram in loco um treino de pesquisa intenso. Só a grandeza da qualidade dos dados colhidos por Anastasya tornou possível a escrita deste texto. Neste trabalho de campo também contámos com a participação ativa do Professor Gerson Tavares que estava, nessa altura, a desenvolver um projeto de pesquisa sobre a permanência escolar, sob a orientação do Professor José Manuel Resende. Inserido no centro de pesquisa CICS.NOVA, o professor Gerson Tavares da Universidade Estadual Norte Fluminense Darcy Ribeiro esteve conosco até julho de 2018.

6- Nas relações de afetação ocorridas entre uns e outros na escola, o propósito neste artigo é observar como o outro - aluno, colega ou amigo de nacionalidade portuguesa - é identificado por um ser notificado como estrangeiro, mas que estando matriculado como aluno se apresenta nesse território com igual equivalência estatutária, regulada pelo estatuto do alunado. Contudo, e seguindo os alertas deixados por Breviglieri (2016), em muitas ocorrências experimentadas pelo ser, de fora, que capta o ser de dentro - 0 olhar do estrangeiro sobre o nativo - a antropologia capacitária que se liga à luta pelo seu reconhecimento na escola tem de ser vista com cautela. A sua identificação atribuída pelo outro nativo com quem vai estabelecendo laços ao longo do tempo de permanência na escola vai sendo o resultado de experiências plurais e diversas, onde a capacitação de si face ao outro nem sempre é o resultado de reciprocidades esperadas, e, por isso, o reconhecimento de si como estrangeiro face ao outro que é nativo atravessa experiências penosas, sofridas, e nesse sentido, menos prazerosas. A densificação dessas experiências não é automática, leva tempo e requer uma economia da mutualidade (RICOEUR, 2004) entre uns e outros, que vai sendo explorada quase sempre de forma sinuosa. Ter a garantia de que a sua voz seja atendida pelo outro faz-se por tentativas baseadas por gestos ardilosos, com estratagemas delicados. É, nesse sentido, que os compromissos alinhados na reciprocidade vão-se sedimentando lentamente e, quase sempre, por via da philia (RAYOU, 1998).
} 
Daí o cuidado em assinalar dinâmicas miúdas (PIETTE, 1996), quer pela eventual manifestação de fragilidades ou de vulnerabilidades do si enquanto outro, quer para dar conta de elementos que sem esses apontamentos passariam despercebidos. Dar visibilidade a esses aspectos enriquece justamente a descrição de quais são as artes de fazer o comum na sua pluralidade na escola, mas não deixando igualmente de assinalar nessa exposição as maneiras de tecer esse comum, que é feito de hesitações, de receios, de apreensões, e até mesmo de questionamentos que levam o si mesmo enquanto o outro a ir e vir entre múltiplas referências.

É disso que importa mencionar quando os laços do aluno na figura do estrangeiro são ensaiados com os outros na escola, em diversas ocasiões e circunstâncias. Quais são as ligações mais confortáveis observadas nessa escola em que a sua dignidade não é posta em causa perante os outros? E quais são as inversas em que a voz do aluno qualificado de estrangeiro manifesta a sua estranheza e por meio dela expõe seus incômodos, seus embaraços?

$\mathrm{Na}$ verdade, a habitabilidade da escola não deixa de conter essas composições, por vezes tão imbricadas justamente pela sua complexidade. Há, por isso, que tomar em consideração do ponto de vista analítico esse ir e vir entre o conforto e o consolo de se estar na escola e, simultaneamente, de se mostrar na escola a partir de momentos de desencanto, de abatimento, isto é, situações que experimentam a fatiga em face das solicitações e das provas a que estão sujeitos, quer face aos colegas, quer face aos adultos.

\section{A dança das cadeiras: o bar ${ }^{7}$ como local de convivialidade e de aprendizagem de si enquanto outro de igual valia}

É pelas maneiras como esses alunos inquiridos descrevem o modo como habitam a escola que vamos tratar a problemática do reconhecimento, não só na sua manifestação enquanto luta pela sua existência enquanto seres de direitos (HONNETH, 2011), mas também pelo seu lado de uma economia da mutualidade através da generosidade em dar e de receber sem estar em questão a reciprocidade (RAYOU, 1998; RICOUER, 2004). 0 olhar perspicaz é alertado para dar conta do modo como os atos de habitar são compostos pelo reconhecimento na perspetiva da reciprocidade, mas também por momentos em que o doador não recebe nada em troca, a não ser o reconhecimento da generosidade do ato daquele que se entrega a si por dedicação manifesta.

Indo por esses caminhos, para a reflexão, apostamos antes de mais na identificação de locais de encontros. Assim, pelos relatos deixados pela jovem pesquisadora, nota-se que o bar da escola é um local de habituais e excelsos encontros em diversos momentos do dia a dia no estabelecimento de ensino.

$\mathrm{Na}$ verdade, da intensa enumeração de instantes captados, nota-se o esforço em traçar o modo como em um espaço com uma determinada configuração os alunos se movimentam em um entrar, permanecer e sair constantes. Pelo inventário descrito, apercebemo-nos que o bar é um espaço de uma rotatividade imanente.

7- Em português de Portugal, o termo bar é equivalente a lanchonete no Brasil. 
A convivialidade faz-se na base desses instantes em que estão ali juntos. A natureza quase momentânea como se movimenta de mesa em mesa, com ajuntamentos diversos torna difícil a identificação de quem entra, de quem permanece e de quem sai dali para outras paragens.

A impossibilidade de o olhar externo identificar quem é quem em ocasiões como aquelas obriga a aprendiz de etnógrafa a usar outros equipamentos, nesse caso, peças do vestuário para conferir algum sentido àquelas movimentações. São tentativas de composição que não são fáceis para manter o rigor da observação, uma vez que o rebuliço naquele território da escola ganha o signo da sua natureza agitada, quando não efervescente.

Tomemos esse exemplo de captação de uma dessas ocasiões:

Enquanto isso, o grupo de jovens com sweater azul (do Brasil) entra novamente dentro do bar. Nesse momento, a professora que os acompanhava e lhes mostrava o bar sugere que parem. Aí, vira-se para os alunos sentados nas mesas, perguntando alto “Quem aqui é do Brasil?”. Nesse momento, o aluno que estava sentado na mesa ao lado da aluna estrangeira que estava sozinha, estando acompanhado por um colega de origem estrangeira e uma colega de sweater vermelha, disse "Eu sou". A professora chamou o aluno, pedindo para este conversar com os jovens do Brasil. Paralelamente, o discurso do aluno e da professora era abafado pela música que os alunos sentados na mesa à nossa direita passavam, ao lado dos cacifos. (DIÁRIO DE BORDO).

A professora quando entra no bar com um grupo de alunos estrangeiros que vão visitar a escola convoca para se juntar a esse conjunto um aluno da escola da mesma nacionalidade daqueles que acabam de chegar. Quem é aqui do Brasil?

Em face do barulho, e na difícil tarefa em identificar pelo nome os alunos presentes, usa a nacionalidade para aquela demanda. Facilitam-se as trocas recíprocas se alguém for de imediato reconhecido como uma pessoa que possa facilitar a intercomunicação entre quem permanece e quem acaba de chegar, mas que está de visita (SIMMEL, 1999; 2004). Assim, nessa circunstância, o uso costumeiro da convenção faz todo o sentido (WEBER, 1993; BOLTANSKI; THÉVENOT, 2006). E dela sobressai a identificação pelo registro da nação à qual se está ligado.

É por essa forma de qualificação que a conversação se faz, apesar de não ter havido a possibilidade de acompanhar os teores daquelas prosas. São falantes de uma mesma língua, mas com sotaques diferentes, e com o uso de algumas palavras que não comportam os mesmos significados em um e no outro contexto linguístico. A empatia imediata faz-se pela companhia de falares com trejeitos comuns.

Desta vez, era música eletrónica. Estes alunos riam alto, enquanto mexiam nos seus telemóveis ${ }^{8}$. Contudo, ouviu-se a professora perguntar ao aluno brasileiro "Há quantos anos estás aqui?". Em breve, a professora agradeceu ao aluno e dirigiu o grupo de jovens de sweater azul para fora do bar. (DIÁRIO DE BORDO).

Essa cena é finalizada pela escuta da pergunta que a docente faz ao aluno da escola que se identificou como sendo da mesma nacionalidade dos jovens que tinham ido à

8- Telemóvel é o equivalente a celular nos falantes de português no Brasil. 
escola como visitantes. Nada mais foi possível ouvir das conversas havidas. As músicas que saíam dos telemóveis eram audiveis em tom alto, e alternavam entre o género hip-hop e o género eletrónica9 9 .

Entretanto, [continua a contar-nos a observadora] mais três alunos entram no bar e arranjam três cadeiras. Enquanto dois se sentam ao nosso lado esquerdo, de costas para os cacifos, um dos alunos arrasta a cadeira até a mesa onde estava sentado o aluno brasileiro, outro aluno com origem estrangeira e uma aluna que aparentava ser portuguesa, de sweater vermelha. Olhando para o colega, os outros dois alunos apressaram-se e dirigiram-se, também, para essa mesa. Deste modo, a mesa passou a ser ocupada por uma aluna portuguesa, dois alunos com origem estrangeira e três alunos que também aparentam ser portugueses. (DIÁRIO DE BORD0).

As movimentações continuavam entre o arrastar as cadeiras para compor os grupos e os seus arranjos com a mediação dos telemóveis nas mãos dos alunos que rodavam de mesa em mesa. Tudo era registrado pela participante avulsa como se de uma cenografia dançante se tratasse por debaixo do seu olhar atento.

A sua atenção arguta percebe que após a saída dos jovens brasileiros uma aluna estrangeira que estava no fundo do bar é incluída na conversa com colegas que estavam ali a participar em um ensaio de interpretação e voz. Essa encenação tinha começado antes da entrada dos jovens brasileiros.

Como narra no seu diário, naquele mesmo local tinha decorrido um pouco antes um ensaio teatral desenvolvido por alunos da disciplina de interpretação e voz.

0 grupo era constituído por alunos com origem estrangeira e portugueses, que cantavam e representavam. 0 público espectador estava sentado nas mesas do bar e, em maior quantidade, os alunos que observavam a partir da rampa do refeitório. Durante a performance, observouse que o tema era sobre religião, ouvindo-se palavras como "deus" e "perseguição". Os alunos dispunham-se em círculo e saíam do círculo à vez, projetando-se em várias direções. No final da performance, os alunos voltavam para o seu lugar inicial, progressivamente. Cantavam uma música, em que se repetia "hey lord". Quando acabaram, um professor anunciou que se tratava de

\footnotetext{
9- Tal como é referido por Rayou (1998), os equipamentos sonoros que se ouvem no bar são dispositivos tecnológicos que facilitam múltiplos arranjos que, de um lado, possibilitam criar afinidades que se podem transformar com o tempo em afeições eletivas de cariz amical, mas que do outro lado tornam possível fazer deslizar regimes de envolvimento de ação familiar e de proximidade aos regimes em plano (THÉVENOT, 2006). Desses dois regimes de envolvimento da ação aqui assinalados, os primeiros são experimentados pelos laços da philia (RAYOU, 1998; RESENDE, 2010). Os segundos são firmados pelos trabalhos escolares, individuais ou em grupo, realizados através do computador portátil - laptop. Pelos primeiros, os adolescentes vão ensaiando modalidades políticas de fazer comum na escola e fora dela, usando o humor, as piadas de teor sarcástico etc. Esses ensaios são muitas vezes testes, provas a partir das quais os seres adolescentes a entrar na vida juvenil apreendem na escola, e nos territórios que os circundam, formas e modalidades de agir com ganhos de maturidade, onde as discussões, os bate-bocas cruzam retórica argumentativa cujas fundamentações se vão ajustando àquilo que se espera dos debates que se realizam nas arenas públicas (CEFÄ̈, 2017). É certo que nessas experiências há também o lado lúdico, apartes que entre eles ganham outros sentidos menos comprometidos com as questões públicas. Mas mesmo nesses momentos não é despiciendo afirmar que também pode haver ganhos políticos, por exemplo, quando as piadas sexistas são esteios para discussões sobre a homofobia ou a desigualdade de género (RESENDE, 2010; RESENDE; GOUVEIA, 2013; RESENDE; DIONISIO, 2016).
} 
um ensaio de interpretação e voz, sendo que a peça será apresentada dia 17, num dos intervalos ${ }^{10}$. (DIÁRIO DE BORDO).

Esse local parece ser forçosamente um espaço de passagem para a maioria dos estudantes desse estabelecimento. 0 trânsito era constante, aumentando às horas das pausas das aulas e sobretudo durante os almoços. E, por isso, era previsível intercetar conversas várias entre os seus usuários. Em um dos dias a observadora deu conta da seguinte ocorrência. Em uma das mesas dispostas na sala do bar:

Seis estavam sentadas de forma simétrica, estando três alunas de origem estrangeira sentadas dum lado da mesa e, em frente delas, outras três alunas, aparentemente portuguesas. Contudo, a aluna com origem estrangeira que estava lá anteriormente, estava ligeiramente afastada da mesa, sentada num dos cantos, encostada aos cacifos. Esta aluna continuava a mexer no seu telemóvel, com os fones nos ouvidos e a perna cruzada. Estas alunas estão a almoçar, comendo as suas baguetes e bebendo os seus refrigerantes. As alunas conversavam sobre alguma controvérsia, sendo que algumas delas pareciam indignadas. Uma das alunas, aparentemente portuguesa, diz que "eu não sabia que diziam estes nomes", acrescentando que "não sabia que existia, que ainda existe". A mesma aluna ainda comenta que "é que eu nem sou amarela nem sou preta, não sou amarela". A aluna que estava encostada aos cacifos, comentou "eu sou mais escura", parecendo que comparava a sua cor de pele com outra colega, a propósito de um acontecimento controverso que decorreu com alguma das alunas. As alunas pareciam falar de questões de etnia, ou origem nacional, pois falavam da cor da pele, fazendo referência a algum acontecimento, em que, pelos vistos, alguém deu um uso pejorativo ao termo "preto". É de notar que, das alunas que estavam presentes, a que pareceu mais crítica e mais se expressou sobre o assunto foi uma aluna que parecia portuguesa, sem qualquer sotaque. A aluna parecia envolvida na causa das colegas, mostrando-se protetora, ao mesmo tempo que censurava as pessoas que "diziam estes nomes". As alunas parecem indignadas e, a dado momento, chegam-se mais perto umas das outras (exceto a aluna que estava sentada no canto), formando uma espécie de círculo e segredando algo umas para as outras. Durante a interação destas alunas, observou-se que as alunas portuguesas se mostraram muito interativas com as alunas de origem estrangeira, rindose para elas e aproximando-se para segredar. (DIÁRIO DE BORDO).

0 corrupio tem sido a marca da azáfama que se tem descoberto permanentemente naquele espaço pela mão de quem deixa notas no diário. Com cenografias diversas, as movimentações não descansam um minuto. É um entrar e sair para comprar qualquer coisa para mordiscar, para dar ao paleio, para se ouvir piadas e bocas cruzadas, mas também para se assistir a dinâmicas interativas mais prolongadas, como é expresso no excerto anterior. E coincidiu a jovem pesquisadora dar conta de um acontecimento

10- Aqui está um exemplo em que as artes de fazer o comum se experimentam num local mais destinado ao convívio do que a assistir a um ensaio teatral. Ao reduzir-se a bagunça no bar, este espaço permite que os alunos dessem atenção, com a menor perturbação possível, ao ensaio de interpretação e voz que está ali a realizar-se. 0 professor usa o bar/lanchonete como plateau, para fazer esta exibição, expondo os atores do espetáculo em confronto com uma audiência que não foi avisada previamente que tal acontecimento ocorria no momento de pausa entre aulas. $\mathrm{E}$ esta audiência improvável fez jus da expetativa esperada, em que as entradas e saídas do bar não foram obstáculo ao desenrolar do ensaio, criando um desassossego perturbador e incómodo para quem estava a ensaiar a peça. 
inaceitável ter ocorrido na escola, mas que naquelas trocas comunicacionais não foi explicitamente revelado.

Deu-se conta de que se tratou de um problema que as indignou e que dizia respeito a comportamentos de teor racista. Tal conclusão resultou do facto de alguém na escola ter usado a palavra "preto" depreciativamente em uma ocorrência não descrita nos diálogos estabelecidos naqueles instantes. Com o problema, a celeuma desponta com acervos de argumentações a partir da cor da epiderme de cada uma que entra naquela conversa cruzada. A incompreensão é geral, porque lhes parece inaudito ainda hoje existir fenómeno como aquele que as indigna convictamente. No meio dessa conversação, destaca-se uma das colegas que sendo portuguesa se mostra disposta a exercer um regime de envolvimento de cariz mais protetor (BOLTANSKI; THÉVENOT, 2006; THÉVENOT, 2006), censurando aqueles comportamentos inaceitáveis ${ }^{11}$.

E usam coreografia do círculo e do segredar (SIMMEL, 2004) como manifestação de garantia de defesa mútua em face a turbulências injustas que advêm dessas formas de agir injustificadas, porque põem em causa a dignidade da pessoa humana de cada uma delas (RICOEUR, 2004; BREVIGLIERI, 2016; SCHILLING, 2013). 0 itinerário da doação tinha ali acontecido.

E essa doação tem razões morais (JOAS, 2015). A essa provável carapaça que as envolve, metaforizada pelo desenho de uma curva que se fecha, confere ainda outra força às orientações normativas de cariz político que esse agir capacitante parece patentear na ocasião registrada.

Pelo modo como o acontecimento é narrado, não é descartável a possibilidade de essas alunas estarem envolvidas por laços próximos - num regime de envolvimento de proximidade. Ao falarem de um assunto delicado, que em outras circunstâncias se tem mostrado na sociedade portuguesa como questão de difícil e alargado debate, as jovens ao exibirem esse à-vontade em discutirem o assunto em comum expõem-se umas às outras.

Esses laços de reciprocidade apresentam um cunho moral. Mostram-se que estão ligadas por laços que lhes conferem a garantia da confiança. E é assim que a maturidade se vai construindo na adolescência com a assunção de que o político, no âmbito das questões públicas, começa a ser uma das provas cruciais para se apresentarem em público (BREVIGLIERI, 2007a).

A voz não é ainda completamente audível em voz alta. Mas a sua preparação é, pelo relato, uma promessa possível que se infere a partir dessa aprendizagem. A argumentação começa por ser de âmbito epidérmico, com um revestimento frágil e pouco apurado. Mas a noção de que as consequências das conversas de teor rácico, a brincar ou a sério, levam à desqualificação do ser já emerge dessa experiência.

\footnotetext{
11- Dá-se nota da cumplicidade que 0 ato de proteção envolve uma aluna - nativa - com as outras que são estrangeiras. A ilação retirada denotando a ideia de proteger alguém que exprime pela sua indignação a identidade magoada (POLLAK, 1993) de quem molestada pelo ato racista, apesar de ser uma manifestação de um regime de envolvimento de proximidade (THÉVENOT, 2006) entre umas e outras, não deixa de deslizar para um outro regime de envolvimento de ação sobre as questões de justiça com uma natureza pública (BOLTANSKI; THÉVENOT, 1991). Ora, nas sociabilidades escolares, as artes de fazer o comum no plural abraçam experiências que tocam 0 íntimo - a colega que se sentiu discriminada - mas que permitem igualmente a travessia para o lado público, em que o ato racista é ajuizado como um ato injusto, desrespeitando a humanidade comum a que todos têm direito. Não reconhecendo o outro como si mesmo (RICOEUR, 1990), aquele que é apontado como diferente por causa da sua cor da pele sente-se diminuído, e a sua capacitação para agir de modo autónomo pode ser suspensa ou evitada (ELIASOPH, 2010) para não criar confusão.
} 
A incrédula descoberta da persistência dessa maneira de qualificar os outros faz surgir na indignação a ideia de uma não equivalência entre humanidades que se equipam como distintas. Usar pejorativamente a cor da pele preta é reduzir a humanidade de quem nasce com ela. E isso é inaceitável e intolerável (BREVIGLIERI, 2009).

Pela prova dada pela colega portuguesa de querer dar a garantia de uma qualificação política às outras colegas estrangeiras, a compostura corporal dava também motivo a certo relaxamento. Podiam contar com a sua voz solidária.

A disposição circular parece representar a metáfora da garantia e da confiança mútua em preservarem a humanidade que transportam pelo corpo de cada uma. Escudadas pela linha circular, encerradas no círculo, sentiam que o momento sequencial era a do riso e das piadas. As visadas não estavam sozinhas nesse embate. A possível exclusão por aquilo que tinha ocorrido e que as fragilizou era para já passado.

Mesmo se na eventualidade naquilo que tinha acontecido não as tenha envolvido diretamente, há o reconhecimento de que um dia podem vir a estar na berlinda. Daí as apreensões, os receios que estavam ali presentes. Mas, simultaneamente, apercebiam-se que podem ter o direito à indignação. E isso assegurava-lhes a realização de si enquanto um outro de igual dignidade. Esta aprendizagem permite cunhar experiência de um regime de envolvimento sobre as questões do justo (BOLTANSKI; THÉVENOT, 2006; RICOUER, 1995, 2004).

0 sossego e o conforto em habitar a escola são preservados. Daí as emoções do relaxamento corporal (BREVIGLIERI, 2012).

\section{A fechar para voltar a reabrir: entre nem tudo são peras doces e as afinidades bem-sucedidas nas sociabilidades escolares}

Como referido, os territórios escolares em Portugal têm sido nas últimas décadas habitados por crianças, adolescentes e jovens oriundos de diferentes contextos étnicos e nacionais. Talvez a sua visibilidade política se tenha elevado na transição do século XX para o século XXI. Os diferentes ciclos de imigração têm dado prova desse crescimento numérico com incidências maiores nas morfologias de estabelecimentos de ensino nas duas grandes áreas metropolitanas do país: Lisboa e Porto ${ }^{12}$ (PIRES, 2003).

A localização litorânea dessas metrópoles aguça a fixação das famílias que vindas de fora pretendem em Portugal restabelecer as suas vivências familiares com garantias de segurança e de bem-estar. São territórios onde é mais fácil encontrar trabalho, quer para forças de trabalho qualificado, quer para mão de obra menos qualificada. A sua atração não é novidade, uma vez que exerceu nos anos 50 o mesmo predomínio aquando das migrações internas, de norte a sul do país (MACHADO, 1994, 1997).

Não obstante essa tendência, isso não significa que não haja famílias de imigrantes instaladas em outras regiões. Os polos universitários, as atividades do turismo e do setor agrícola exercem hoje um certo motor para uma menor concentração desses agregados

12- A integração do aluno estrangeiro no sistema de ensino português espelha os padrões de distribuição e residência da população estrangeira que se encontra em Portugal. Desta forma, verifica-se a afluência dos alunos estrangeiros matriculados no ensino básico e secundário na região de Lisboa (NUT II) com 56,7\% dos alunos estrangeiros e a região Norte com 13,3\% (OLIVEIRA; GOMES, 2019). 
familiares nas grandes áreas metropolitanas (RODRIGUES et al., 2013; FONSECA, 2008; MACHAD0, 2003).

Por isso, compor o reconhecimento nos estabelecimentos de ensino portugueses também passa por dar visibilidade a essas experiências agora trazidas por vozes e corpos de alunos de outras nacionalidades. Esses confrontam-se com a novidade ao fazerem a matrícula em uma escola ainda desconhecida ou em vias de a conhecerem a fundo.

Ao chegarem ao início de cada ano letivo, defrontam-se com outras paisagens humanas, arquitetónicas, de calendário, de usos dos tempos e dos espaços na escola e fora dela, das ofertas escolares, dos graus de exigências quanto à aquisição dos conhecimentos, tudo isso aferido por comparações que fazem a partir de experiências anteriores, nomeadamente das experiências havidas nos países de origem. Ora, enfrentar o novo não é fácil, porque exige acomodações várias quer com os novos colegas da turma e da escola, quer com os professores, quer ainda com outros profissionais que ali trabalham em diversos setores.

0 quadro trazido pela novidade de quem está a entrar pela primeira vez comporta o cuidado em fazer as tessituras que o novo ser tem de produzir sob o comando da precaução. Como ainda não conhece o terreno que pisa, vai reconhecendo que os exercícios corporais, concebidos no seu todo, têm de ser exercidos com idas e vindas, com hesitações, com receios e, em algumas ocasiões, com alguns sustos.

Assumir esse cuidado significa exercer o princípio do comedimento no contato que começam a fundar com os outros que ainda são para si seres a conhecer. Nesse sentido, não deixam de realizar apreciações diversas sobre o ambiente a que estão a ensaiar a consumação das suas ligações entre uns e outros.

Essas são feitas passo a passo, com cautelas acrescidas, porque pretendem evitar a tudo o custo que depreciem ou desconsiderem a sua pessoa na humanidade que transportam em si. Estar de atento às possiveis experiências incomodativas fá-los apresentarem-se com tibieza e manifestando perplexidades e indecisões.

Expõem-se devagar. Não revelam tudo de repente. Resguardam-se até ver se é possível estabelecer laços de reciprocidade. 0 caso da indignação pela experiência da discriminação racial é disso um exemplo. 0 círculo é a imagem de um espaço protegido, confidencial, de cumplicidades e de relaxamentos, que se por um lado se fecha sobre si, por outro lado, o conforto ali tecido pelo habitat de proximidade abre-lhes outras possibilidades de se preparem para uma exposição pública futura usando a crítica para repudiar as consequências de atos racistas.

Dão-se conta pelas experiências iniciais que não estão ainda garantidas a confiança de si perante outros com quem mantêm relações circunstanciais, com certa discrição. Avaliam tateando.

Agem com indecisões. Omitem capacitações ou então suspendem-nas até outras oportunidades ou possibilidades futuras. Sendo um futuro ainda muito incerto, sentemse intimidadas. Face a situações inesperadas, nem sabem como fazer ou o que é ajustado fazer. Revelam as suas vulnerabilidades.

Exato. E, às vezes, eu acho [HESITAÇÃO] se eu tipo, tem um grupinho, eu tenho [HESITAÇÃO] acho que não é bem vergonha, mas medo de [PENSATIVA] intervir e chegar, do nada. Então, eu fico meio apreensiva. (DIÁRIO DE BORDO). 
Os receios manifestados por essa aluna brasileira acabada de chegar à escola são reveladores das fragilidades assumidas por quem ainda não achou onde botar as suas âncoras. Teme expor-se, porque chegou do nada. Ainda não é alguém no grupinho.

No meio do nada há gestos de mutualidade. "Sim, sim", continua a responder sobre os modos de acolhimento que tem experimentado na escola.

Eu acho que eles chegam. Por exemplo, eu [REFORMULA] houve um dia em que fiquei aí no meu canto. Aí, as duas meninas que tavam, me chamaram. "Não, não tem medo, a gente pode chegar e ficar, e ficar com a gente". (DIÁRIO DE BORDO).

A entrevista continua em torno do acolhimento depois da chegada à escola. E vai dando nota de que o reconhecimento de si como um outro tece-se gradualmente, com dúvidas, hesitações, mas, ao mesmo tempo, com a garantia de que, devagar, chega a âncora que tanto anseia para se sentir segura.

Sim, sim. Acho que fui muito bem acolhida. Porque, eu até brinco [RISO], falo, no Brasil não tem essa [HESITAÇÃO]. Por exemplo, se chega um aluno novo na sala, é depois de um certo tempo que vai [HESITAÇÃO]. Aqui, eu achei que eles já foram, tipo, falar comigo e tal. Mesmo tendo uns ou outros que são mais na deles, não falaram ainda, eu acho que é porque é um elemento novo, uma coisa nova que está na turma. Então, demora um pouco mesmo para [HESITAÇÃo]. (DIÁRIO DE BORDO).

A intrusão na turma é um sucedâneo de tempos para se darem a conhecer uns aos outros. Os laços são ainda ténues, primeiro aproximam-se de uns, mas há outros que continuam indiferentes à sua presença. Estão na deles, isto é, a preposição "de" ainda não cola com o pronome pessoal "eles". A estudante ainda não é uma entre eles. Mas entende a demora justamente porque é nova na turma. É nesse sentido que as artes de fazer o comum no plural envolvem todas essas aprendizagens. A acolhida é prometida pelo grupo de pares. Não é ato rápido. Com o tempo vai-se compondo. E parte-se da experiência proximal para a inclusão na turma e depois na escola.

E prossegue a falar de si na sua relação com os outros.

Sim, apreensiva mais em relação às matérias, que para mim está muito difícil realmente. E [PENSATIVA] em contexto de amizade, sabe? De estar atrapalhando ou não. E eu sou um pouco paranoica [RISO]. Eu vejo uma pessoa [REFORMULA] conversando e tá olhando para mim, eu já acho que está falando de mim. Então eu sou [HESITAÇÃO; APREENSIVA] assim. (DIÁRIO DE BORD0).

0 receio de estar a ser avaliada é também uma constante dos temores de quem chega ao desconhecido. Não sabe como a vêm como pessoa humana, e, por isso, assume a desconfiança. Ainda não tem chão seguro.

Outro exemplo reforça o reconhecimento das fragilidades de quem entra numa escola que não é ainda a sua escola. Essa ficou distante no país do seu nascimento. Um aluno angolano está-se a fazer à entrada na escola, porque ainda tem pouco tempo no estabelecimento. Na 
entrevista, é confrontado a falar sobre o modo como os colegas o abordaram em seu primeiro dia na turma, duas semanas após o ínicio das aulas.

E quando cheguei, eu olhei para a turma e vi. Epá, era muito estranho. Muitas pessoas diferentes. E olharam para mim, tipo a rir, etc., porque gostaram. Nunca tiveram praticamente um preto na sala, e essas coisas assim. E a minha stora ${ }^{13}$ pediu para eu me apresentar, que era a minha diretora de turma. Eu fui para lá e nem consegui olhar para eles. Estava a olhar para o chão. Dizia o meu nome, a minha idade. E quando eu disse a minha idade, também eles ficaram muito espantados, porque naquele tempo eu tinha 15 anos e eles disseram "Tens corpo de 15, parece que tens já 17, 16", ou uma coisa assim. (DIÁRIO DE BORDO).

A revisitação da primeira abordagem leva-o a uma avaliação da sua singularidade na turma. Pela primeira vez, tomavam conta na sala de um aluno preto, no dizer do jovem. Não obstante essa identificação por si assumida feita pelos outros, esses apreciaram a sua vinda, porque riram da sua apresentação mesmo olhando para o chão. Essas são as notas das primeiras impressões captadas por si a partir da maneira como os outros da turma, em particular os colegas nativos.

Face à surpresa de se ter de apresentar à turma, não teve coragem de olhar os rostos dos colegas. Escondeu o seu rosto baixando-o em direção ao chão. Sentiu-se assim mais seguro, salvaguardado. 0 espanto demonstrado quanto à sua idade biológica foi outro ingrediente que não lhe saiu da memória. Parecia aos outros mais velho. A corporalidade mais encorpada dálhe, nos olhares dos outros, um perfil de jovem quando ainda é um adolescente.

$\mathrm{Na}$ escola não se estava sozinho. Dois primos também tinham se matriculado no mesmo estabelecimento de ensino. Isso impediu que sentisse a solidão resultante de ser novo na escola, como aconteceu com a colega de nacionalidade brasileira.

[Depois] encontrei mais um angolano. Começou a falar comigo e devido aos lugares, já sentei com outro colega, que fazia parte da planta. Comecei a falar com ele. A partir dele, comecei a falar com os outros. E na primeira aula de educação física, nós jogámos futebol. E eu, como sou mesmo bom a futebol, gostaram de me ver a jogar, e etc. E foi aí que eles começaram "Esse gajo é fixe", uma coisa assim. (DIÁRIO DE BORDO).

Se a experimentação de um jogo coletivo deu um empurrão para a inclusão bemsucedida, foi a sua maneira de ser que fez engrenar os laços que se sucederam na turma e fora dela. Afirma "não fiz assim amizades por causa do futebol. Mas sim, por causa da minha maneira de ser”. E adianta dando fundamentos àquele juízo.

Acho que gostam da minha maneira de ser. Sou um pouco divertido. E, também não tenho vergonha de falar com as pessoas. Não sou assim tão tímido. Então, e achei que as pessoas não

13 - É o diminutivo de senhora doutora. Em linguagem do alunado, a professora é denominada como stora. 
são assim tão tímidas e falam comigo também. Eles são muito bons, os amigos também. Acho que agora não houve falsidade. (DIÁRIO DE BORDO).

Ser alegre ajudou-o a consolidar as suas relações com os outros. E confirmou que foi bem recebido, porque há afınidades quanto ao seu lado destemido, desinibido. Ganhou alento e mantém a mesma tónica. Avança:

\begin{abstract}
Gosto de andar sempre com um amigo. E se eu não tivesse, ia andar praticamente sozinho. Estar aí sempre num sítio, a ouvir música, ou uma coisa assim [...]. Já vi que pessoas assim não têm muitas relações. E não é algo muito bom. Tem que explorar também umas coisas. [...] Eu aqui tenho um amigo, até esqueci, tenho dois. Ando muito com eles. E, um deles, como não é da minha turma e dá-se sempre comigo, está sempre a ligar para mim. Quando toca, e já saímos da turma, não sei onde é que ele está, porque a escola é um pouco grande e ele liga para mim "Olha, estás onde? Vamos dar uma volta”, ou algo assim. Sim, eu acho que é muito bom.
\end{abstract}

Explorar faz parte da sua experiência (AURAY, 2007; AURAY; VETEL, 2013). Ficar só não cola consigo. Para evitar a solidão é experimentar o ambiente a que ele se encontra ligado. Confessa que essa experimentação lhe foi facilitada por ter um amigo nessa escola e na sua turma. Esse participou nas apresentações mútuas:

[...] porque nós, como já andávamos juntos, ele começou a dar-se com algumas meninas, apresentou-me essas meninas, apresentou-me os rapazes. E, ele é que me ajudou a interagir mais com as pessoas aqui. Foi mesmo ele. [E esse ele era um nativo do País]. (DIÁRIO DE BORDO).

É por essas matrizes com diversas entradas que o reconhecimento é ou não sentido por quem acaba de chegar à arena pública que é a escola em Portugal. Essas não são dualidades imbrincadas uma e na outra. Ao invés, apresentam-se combinadas, envolvidas, requisitando plurais artes para as compor. Compõem-se por experimentações, tal como se observou no espaço do bar/lanchonete do estabelecimento de ensino.

Essas não surgem como arte inaugural. Vão-se fazendo com investidas a múltiplas velocidades. Os jeitos de as tecer não excluem os nós, as interjeições misturando reclamações com aclamações. Tudo depende das situações, dos acontecimentos e das consequências retidas por quem as experimenta no dia-a-dia. Tropeça-se para depois levantar, ergue-se para não voltar a cair. Tenta-se que isso não aconteça. É o que também resulta do espanto que ainda há quem não respeite quem é diferente, porque é de uma outra origem étnica. Tenta-se não cair em excessivas inquietações, nem no medo que paralisa o envolvimento naquilo que é comum a todos. 0 círculo que protege é também o espaço que fortalece e que as treina para o confronto público.

É isso que irriga a maturação dos seres na escola. Nada nessas composições é escuro ou claro, sombrio ou luminoso. As tonalidades variadas acompanham os seus arranjos num ir e vir constantes, em que as convicções seguras se combinam com as dúvidas e as hesitações. Tudo são promessas por cumprir nas autonomizações capacitantes que se desejam erguer através destas e de outras aprendizagens que a escolarização oferece. 
É nesse sentido que a socialização escolar tem uma natureza política (RESENDE, 2010), porque aspira a que as vinculações entre os seres de grandeza pequena se liguem aos seus ambientes como primeiras experimentações para aprenderem a estar em público. É pelas experiências inicialmente titubeantes que os adolescentes vão sabendo exporse mesmo em discordância ou segundo outras ordenações desarranjadas (BREVIGLIERI, 2007b). As sociabilidades escolares não são tubos de ensaio em que o ser se formata a partir de moldes aperfeiçoados. São, ao invés, composições de reconhecimentos a explorar entre uns e outros.

\section{Referências}

ALMEIDA, Ana Nunes; VIEIRA, Maria Manuel. A escola em Portugal. 1. ed. Lisboa: Imprensa das Ciências Sociais, 2000.

AURAY, Nicolas. Folksonomy: the new way to serendipity. Communications and Strategies, Montpellier, v. 65, p. $67,2007$.

AURAY, Nicolas; VÉTEL, Bruno. L'exploration comme modalité d'ouverture attentionnelle. Design et régulation d'un jeu freemium. Réseaux, Marne-la-Vallée, v. 182, n. 6, p. 153-186, 2013.

BOLTANSKI, LUC; THÉVENOT, Laurent. On justification: economies of worth. 1. ed. New Jersey: Princeton University Press, 2006.

BREVIGLIERI, Marc. L'arc expérientiel de l'adolescence: esquive, combine, embrouille, carapace et étincelle. Éducation et Sociétés, Louvain-la-Neuve, v. 19, n. 1, p. 99-113, 2007a.

BREVIGLIERI, Marc. L'espace habité que réclame l'assurance intime de pouvoir:un essai d'approfondissement sociologique de l'anthropologie capacitaire de Paul Ricoeur. Études Ricoeuriennes/Ricoeur Studies, Pittsburgh,v. 3, n. 1, p. 34-52, 2012.

BREVIGLIERI, Marc. L'insupportable: I'excès de proximité, l'atteinte à l'autonomie et le sentiment de violation du privé. In: BREVIGLIERI, Marc; LAFAYE, Claudette; TROM, Danny (ed.). Compétences critiques et sens de la justice. Paris: Economica, 2009. p. 125-149.

BREVIGLIERI, Marc. Ouvrir le monde en personne. Une anthropologie des adolescences. In: BREVIGLIERI, Marc; CICCHELLI, Vincenzo (ed.). Adolescences méditerranéennes: l'espace public à petits pas. Paris : L'Harmattan, 2007b. p. 19-59.

BREVIGLIERI, Marc. Pensar a dignidade sem falar a linguagem da capacidade de agir: uma discussão crítica sobre o pragmatismo sociológico e a teoria do reconhecimento de Axel Honneth. Terceiro Milênio, Campos dos Goytacazes, v. 1, n. 6, p. 11-34, 2016.

CAETANO, Pedro. A socialização política no plural. Educação \& Sociedade, Campinas, v. 37, n. 137, p. 1045-1060, 2016. 
CAETANO, Pedro. Melhorar o mundo, a escola e a si próprio: os caminhos entrecruzados da experiência juvenil. Educação Temática Digital, Campinas, v. 20, n. 2, p. 413-433, 2018.

CANDEIAS, António. Processos de construção da alfabetização e da escolaridade: 0 caso português. In: STOER, Stephen R.; CORTEZÃO, Luiza; CORREIA, José Alberto (ed.). Transnacionalização da educação: da crise da educação à 'educação' da crise. Porto: Afrontamento, 2001. p. 23-89.

CEFAï, Daniel. Públicos, problemas públicos e arenas públicas...: 0 que nos ensina o pragmatismo (Parte 1). Novos Estudos CEBRAP, São Paulo, v. 36, n. 1, p.187-213, 2017.

DGEEC. Direcção-Geral de Estatísticas da Educação e Ciência. Perfil do Aluno 2017/2018. 1. ed. Lisboa: DGEEC, 2019.

DIONÍSIO, Bruno. Políticas da reversibilidade: extensões e opressões da justiça escolar. Educação Temática Digital, Campinas, v. 20, n. 2, p. 455-474, 2018.

ELIASOPH, Nina. L'évitement du politique: comment les américains produisent l'apathie dans la vie quotidienne. 1. ed. Paris: Economica, 2010.

FONSECA, Maria Lucinda. Imigração, diversidade e novas paisagens étnicas e culturais. In: LAGES, Mário Ferreira; MATOS, Artur Teodoro (ed.). Portugal: percursos de interculturalidade: contextos e dinâmicas. v. 2. Lisboa: ACIDI, 2008. p. 49-96.

HONNETH, Axel. Luta pelo reconhecimento: para uma gramática moral dos conflitos sociais. 1. ed. Lisboa: Edições 70, 2011.

JOAS, Hans. A secularização conduz à decadência moral? Sociologias, Porto Alegre, v. 17, n. 39, p. 224-246, 2015.

MACHADO, Fernando Luís. Contornos e especificidades da imigração em Portugal. Sociologia, Problemas e Práticas, Lisboa, n. 24, p. 9-44, 1997.

MACHADO, Fernando Luís. Imigração e imigrantes em Portugal: parâmetros de regulação e cenários de exclusão. Sociologia, Problemas e Práticas, Lisboa, n. 41, p. 183-188, 2003.

MACHADO, Fernando Luís. Luso-africanos em Portugal: nas margens da etnicidade. Sociologia, Problemas e Práticas, Lisboa n. 16, p. 111-134, 1994.

MACHADO, Fernando Luís; MATIAS, Ana Raquel; LEAL, Sofia. Desigualdades sociais e diferenças culturais: os resultados escolares dos filhos de imigrantes africanos. Análise Social, Lisboa, v. 40, n. 176, p. 695-714, 2005.

MEAD, George Herbert. L'esprit, le soi et la société. 1. ed. Paris: Presses Universitaires de France, 2006.

MÓNICA, Maria Filomena. Educação e sociedade no Portugal de Salazar: a escola primária salazarista, 1926-1939. 1. ed. Lisboa: Presença, 1978. 
OLIVEIRA, Catarina Reis; GOMES, Natália. Indicadores de integração de imigrantes: relatório estatístico anual. 1. ed. Lisboa: Observatório da Migrações, 2019.

PEIXOTO, João. Dinâmicas e regimes migratórios: o caso das migrações internacionais em Portugal. Análise Social, Lisboa, v. 42, n. 183, p. 445-69, 2007.

PIETTE, Albert. Ethnographie de l'action: I'observation des détails. 1. ed. Paris: Métailié, 1996.

PIRES, Rui Pena. Migrações e integração: teoria e aplicações à sociedade portuguesa. 1. ed. Oeiras: Celta, 2003.

POLLAK, Michael. Une identité blessée: études de sociologie et d'histoire. 1. ed. Paris: Métailié, 1993.

RAMOS, Rui. Culturas de alfabetização e culturas do analfabetismo em Portugal: uma introdução à história da alfabetização no Portugal contemporâneo. Análise Social, Lisboa, v. 24, n. 103-104, p. 1067-1145, 1988.

RAYOU, Patrick. La cité des lycéens. 1 ed. Paris: L'Harmattan, 1998.

RESENDE, José Manuel. A sociedade contra a escola? A socialização política escolar num contexto de incerteza. 1. ed. Lisboa: Instituto Piaget, 2010.

RESENDE, José Manuel. 0 engrandecimento de uma profissão: os professores do ensino secundário público no Estado Novo. 1. ed. Lisboa: FCT: Fundação Calouste Gulbenkian, 2003.

RESENDE, José Manuel; BEIRANTE, David. Um corpo bonito não satisfaz os atos afetuosos? Investimentos práticos nos corpos e nos desafetos entre adolescentes e jovens convivendo na escola. Terceiro Milénio, Campos dos Goitacazes, v. 2, n. 1, p. 23-37, 2014.

RESENDE, José Manuel; DIONISIO, Bruno. Itinerários à luz da sociologia pragmática: 0 que os lugares comuns fazem à comunalidade escolar. Terceiro Milénio, Campos dos Goitacazes, v. 6, n. 1, p. 7-10, 2016.

RESENDE, José Manuel; GOUVEIA, Luís. As artes de fazer o comum nos estabelecimentos de ensino: outras aberturas sociológicas sobre os mundos escolares. Forum Sociológico, Lisboa, n. 23, p. 97-106, 2013. $2^{\mathrm{a}}$ série.

RESENDE, José Manuel; GOUVEIA, Luís; BEIRANTE, David. Hospitalidade e acolhimento integrador na arquitetura do comum nas sociabilidades escolares. Cadernos de Pesquisa, São Paulo, v. 50, n. 177, p. 641-659, 2020.

RESENDE, José Manuel; MARTINS Alexandre Cotovio (ed.). The making of the common in social relations. 1. ed. Newcastle: Cambridge Scholars Publishers, 2015.

RICOEUR, Paul. Le juste. 1 ed. Paris: Esprit, 1995.

RICOEUR, Paul. Parcours de la reconnaissance: trois études. 1. ed. Paris: Stock, 2004.

RICOEUR, Paul. Soi-même comme un autre. 1. ed. Paris: Le Seuil, 1990. 
RODRIGUES, Maria de Lurdes et al. Um Portugal de imigrantes: exercício de reflexão sobre a diversidade cultural e as políticas de integração. Da Investigação às Práticas, Lisboa, v. 4, n. 1, p. 82-105, 2013.

RODRIGUES, Maria de Lurdes et al. A construção do sistema democrático de ensino. In: RODRIGUES, Maria de Lurdes (ed.). 40 anos de políticas de educação em Portugal: a construção do sistema democrático de ensino. v. 1. Coimbra: Almedina, 2015. p. 35-88.

SCHILLING, Flávia. Igualdade, desigualdade e diferenças: o que é uma escola justa. Educação e Pesquisa, São Paulo, v. 39, n. 1, p. 31-48, 2013.

SEABRA, Teresa. Adaptação e adversidade: 0 desempenho escolar dos alunos de origem indiana e caboverdiana no ensino básico. 1. ed. Lisboa: ICS-UL, 2010.

SEABRA, Teresa et al. Trajetos e projetos de jovens descendentes de imigrantes à saída da escolaridade básica. 1. ed. Lisboa: Alto-Comissariado para a Imigração e Diálogo Intercultural, 2011.

SETTON, Maria Graça Jacintho; MARTUCCELLI, Danilo. A escola: entre o reconhecimento, o mérito e a excelência. Educação e Pesquisa, São Paulo, v. 41, n. esp., p. 1385-1391, 2015.

SIMMEL, Georg. As metrópoles e a vida mental. In: SIMMEL, Georg. Fidelidade e gratidão e outros textos. Lisboa: Relógio d’Água, 2004. p. 75-94.

SIMMEL, Georg. Sociologie: études sur les formes de la socialisation. 1. ed. Paris: Presses Universitaires de France, 1999.

STAVO-DEBAUGE, Joan. Qu'est-ce que I'hospitalité? Recevoir l'étranger à la communauté. 1. ed. Montréal: Liber, 2017.

THÉVENOT, Laurent. L’action au pluriel: sociologie des régimes d'engagement. 1. ed. Paris: La Découverte, 2006.

THÉVENOT, Laurent. Making commonality in the plural on the basis of binding engagements. In: DUMOUCHEL, Paul; REIKO, Gotoh (ed.). Social bonds as freedom: revisiting the dichotomy of the universal and the particular. New York: Berghahn, 2015. p. 82-108.

VIEIRA, Maria Manuel. Famílias e escola: processos de construção da democratização escolar. In: VIEIRA, Maria Manuel et al. (ed.). Democratização escolar: intenções e apropriações. Lisboa: Centro de Investigação em Educação-FC/UL, 2003. p.75-193.

WEBER, Max. Fundamentos da sociologia de Max Weber. Porto: Rés, 1993.

Recebido em: 26.05.2020

Revisado em: 10.11.2020

Aprovado em: 24.11.2020 
José Manuel Resende é membro colaborador do Observatório Permanente da Juventude do CICS da Universidade de Lisboa e consultor externo do Instituto Nacional de Estudos Comparados em Administração de Conflitos (INCT/InEAC) da Universidade Federal Fluminense em Niterói, RJ. Membro colaborador do Programa de Pós-Graduação em Políticas Sociais da Universidade Estadual do Norte Fluminense Darcy Ribeiro (UENF, RJ); consultor externo do Instituto Vladimir Herzog de São Paulo. Membro do coletivo Pragmaticus.pt.

Luís Gouveia é investigador integrado no CICS.NOVA - Centro Interdisciplinar de Ciências Sociais, Lisboa; Professor adjunto convidado na Egas Moniz - Cooperativa de Ensino Superior. Membro do coletivo Pragmaticus.pt.

David Beirante é investigador integrado no CICS.NOVA - Centro Interdisciplinar de Ciências Sociais, Lisboa, onde integra o Grupo de Investigação em Educação, Conhecimento e Cultura. Licenciado em matemáticas aplicadas, mestre em ciências da educação e doutorado em sociologia da educação, do conhecimento e da cultura. Membro do coletivo Pragmaticus.pt.

Lucas Freitas de Souza é doutorando em sociologia, no Centro Interdisciplinar de Ciências Sociais no polo Universidade de Évora. Membro do coletivo Pragmaticus.pt e do Grupo de Pesquisas em Política Pública e Dinâmica Social. Pesquisador associado na Border Conhecimento e Inovação. 